\title{
Maternal stress and depressive symptoms and adolescents' body mass index: a prospective study
}

\author{
Maaike Koning ${ }^{1,2^{*}}$ (D) Jacqueline Vink ${ }^{1}$, Tommy L. S. Visscher ${ }^{3}$ and Junilla Larsen ${ }^{1}$
}

\begin{abstract}
Background: Growing evidence suggests that maternal mental health issues are associated with (young) children's weight outcomes. However, most studies have been limited by cross-sectional designs and have been aimed at (younger) children. The current prospective study focuses on the link between maternal mental health (i.e., psychological stress and depressive symptoms) and adolescents' zBMI development.

Methods: The participants in the present study were part of wave 1 and 2 of a longitudinal study on Dutch adolescents' and their parents' health behavior. Adolescents (aged 10-14) and their parents were recruited through six secondary schools in the South and the East of the Netherlands. For this study, we only included biological mothers and their adolescent children who participated in both waves, with data on the main measures in both waves, leaving a final sample of 336 biological mother-child dyads. Adolescents height and weight were measured, and both parents and adolescents filled in validated questionnaires on perceived stress and depressive symptoms and answered additional questions concerning domain-specific stress. Regression analyses were performed in R to examine longitudinal links between maternal stress and depressive symptoms at baseline (T1) and adolescents' BMI standard deviation scores (zBMI) 6 months later (T2), corrected for baseline zBMI and covariates.
\end{abstract}

Results: Maternal general perceived stress ( $\beta=.20, p=.002$ ) at T1 preceded higher adolescents' zBMI at T2, after controlling for baseline zBMI and other covariates, whereas maternal depressive symptoms at T1 $(\beta=-.05, p=.44)$ and other domain-specific stress did not (maternal financial stress, maternal stress at work, maternal stress at home). Additionally, lower educational level among adolescents $(\beta=.16, p=.001)$ and adolescent depressive symptoms $(\beta=.16, p=.001)$ was associated with a higher zBMl at T2.

Conclusions: Results suggest that maternal general stress, but not depressive symptoms, may influence adolescents' weight development. Our findings warrant future investigation on whether and how general stress among mothers may predict weight increases of their adolescent offspring.

Keywords: Longitudinal study, Adolescence, Overweight, Maternal stress, Maternal depression, BMI

\footnotetext{
* Correspondence: m.koning@pwo.ru.nl

'Developmental Psychology, Behavioural Science Institute, Radboud University, P.O. Box 9104, 6500, HE, Nijmegen, The Netherlands

${ }^{2}$ Department of Healthy Society, Knowledge Centre for Health and Social work, Windesheim University of Applied Sciences, Zwolle, The Netherlands Full list of author information is available at the end of the article
} 


\section{Background}

Adolescence is a vulnerable period for the development of overweight, a pressing public health issue [1-8], and is characterized by critical changes in body composition, physical activity and eating behaviors, and psychological adjustments $[5,9,10]$. Being overweight and especially being obese as an adolescent increases the risk of becoming an overweight adult [11-15], and has been associated with serious comorbidities in adulthood $[16,17]$. While overweight and obesity have multifactorial causes, parents have a substantial influence on the development of children's and adolescents' eating behaviors [18, 19], food consumption [20-22], and weight gain trajectories $[23,24]$. The role of mothers is especially important because in most households nowadays, mothers are still the most important caregivers [25], and manage most of the day-to-day child-care tasks [26]. They are considered to be the primary gatekeeper of the home food environment [27]. To date, growing evidence suggests that maternal mental health issues (i.e., psychological stress and depressive symptoms) are associated with increased risk rates of weight gain, obesity and related weight-related behaviors (i.e., eating, physical activity and sleep patterns) in children and adolescents [28-38]. However, most studies have been limited by cross-sectional designs and have been aimed at (younger) children. The current prospective study focuses on the link between maternal mental health and adolescents' weight development.

It has been hypothesized that maternal stress and depressive symptoms may influence their child's weight related behaviors through three primary pathways [39]. First, maternal stress may alter mothers' own physical activity, sedentary behavior and dietary intake, which may impact children's and adolescents' behaviors through modelling and household exposure (e.g., less healthy family meals) [40]. Additionally it is known that depressed mothers have difficulty providing healthful food choices [41-43], and modeling physical activity behaviors relative to non-depressed mothers [44]. There is evidence that changes in maternal feeding styles and patterns due to stress and depression can have a significant impact on children's food composition and energy intake by for example preparing convenient but unhealthy meals to help manage time [25, 45]. Second, maternal stress and depression may affect parenting behaviors or mother child interactions. Mothers experiencing high levels of stress may spend less time with their children [46] and may be less responsive in their interaction with their children [47]. Maternal depressive symptoms, such as negative affect and inactivity, can influence child weight related behaviors by directly affecting parenting behaviors, reducing maternal sensitivity to and nurturance of the child's needs $[37,48]$ and by facilitating less positive parent-child interactions and less family cohesion [49-51]. Third, maternal stress and depression can directly influence children's behavior through alterations in the stress response of the child itself [40], responding to maternal stress with an increased biological or psychological stress response .

These pathways explaining the link between maternal mental health and child weight development may particularly be important during adolescence. That is, parents continue to play a decisive role in this age period, for instance through weight-related parenting and specific rules that are associated with greater adolescent nutrition knowledge [52]. This nutrition knowledge may, in turn, prevent unhealthy choices during adolescence when children become more autonomous [52] and are increasingly exposed to more diverse (unhealthier) food environments. Thus, what parents do, both in terms of their own behaviors as well as their food parenting, may prepare adolescents to deal with these more diverse unhealthy food environments, preventing excessive food intake and subsequent weight gain. Moreover, the third pathway explaining the link between maternal mental health and child weight development through child mental health issues may also be particularly important during adolescence, when depression and stress symptoms are more prevalent compared to childhood [53].

To date, previous studies have found that maternal general stress was consistently associated with greater risk for childhood overweight and obesity [28], while the association between depressive symptoms and child overweight was found to be more inconsistent [54], varying by gender and age [55] and measure of depression [54]. Importantly, the majority of studies so far have focused on maternal stress or maternal depression or depressive symptoms exclusively, while longitudinal assessment of both maternal stress and depressive symptoms in relation to childhood and adolescents' BMI are rare. Our study is unique in examining the longitudinal link of both stress and depressive symptoms with adolescents' zBMI development.

Stress may seem to represent one generalizable phenomenon, but there are many sub-classifications of stress, including general perceived stress and perceived stress limited to a specific domain (e.g., financial, workrelated or the home environment) [34]. Each of these different types of stress experienced by mothers may differentially relate to their children's weight-related behaviors and subsequent weight development. For example, financial stress may particularly lead parents to choose low-cost energy-dense food alternatives because of financial constraints [56,57] and has been found to be positively associated with children's weight status [30]. Moreover, higher work-related stress may also particularly result in easy energy-dense food alternative because 
of time constraints. To date, work-related stress among parents of adolescents has been associated with less healthful family food environment characteristics, including less frequent family meals, more frequent fast food for family meals, and less time spent on food preparation [58].

The main aim of the current prospective study is to examine the link between diverse forms of stress, general and domain-specific, and depressive symptoms with adolescents' weight outcomes. Our general hypothesis is that maternal stress and depressive symptoms are linked with increases in adolescents' zBMI over time. Characteristics like educational level of the mother and of the adolescent, adolescents' gender, maternal BMI, maternal marital status, adolescent stress and depressive symptoms, as also the quality of the parent-child relationship rated by parents, will be considered as potential confounding factors for the association of maternal stress and depressive symptoms with adolescent weight outcomes as these are associated with BMI in adolescents [59-70].

\section{Methods}

\section{Participants}

The participants in the current study were part of a longitudinal study on Dutch adolescents' and their parents' health behavior, the " $G(F)$ OOD together" research project. Data for the first three waves were collected in fall 2017, spring 2018, spring 2019 respectively. For this study we used data from the first two waves. Parents of 1657 adolescents were invited to participate, and mothers or fathers provided consent for themselves and their adolescents to participate in the study. Parental consent was provided for 777 parents themselves, of which 593 parents participated in the first wave and for 718 children. Details of the study design can be found elsewhere [71]. For this study, we only included mothers, as they are still the most important caregivers in the family, and are more prone to stress and depression [25, 72, 73] than fathers. In total, 442 mothers took part in Wave 1, 438 in wave 2 (as an extra school was recruited at Wave 2), and $358(81 \%)$ in both waves. Of the $N=358$ with complete maternal data on both waves, we excluded data from non-biological mothers for this study $(n=3)$ and data from mothers of whom there was no anthropometric and questionnaire data available of their adolescent child $(n=19)$, leaving a final sample of 336 biological mother child dyads who participated in both waves. Figure 1 depicts the participation process in a flow chart [74].

Most mothers (97.0\%) were born in the Netherlands. Mean age of mothers at the first wave was 44.6 years $\left(\mathrm{SD}_{\text {age }}=4.2\right.$; age range $=29.8$ to 55.5$)$. Most mothers finished higher professional education (43.3\%) or secondary vocational education (36.7\%) and performed a payed job of less than $32 \mathrm{~h}$ per week (52.5\%) or $32 \mathrm{~h}$ per week or more (19.4\%).

Adolescent boys $(n=161)$ and girls $(n=175)$ were approximately equally represented. Most adolescents were born in the Netherlands (99.1\%). All participants attended regular secondary education $\left(\mathrm{M}_{\text {age }}=12.9\right.$ years; $\mathrm{SD}_{\text {age }}=0.6$; age range $=11.3$ to 14.8 ). In the Netherlands, children in secondary schools follow education based on their academic level and interests. Dutch secondary schools are divided into three streams which represent different educational paths: one to prepare students for vocational training ('VMBO'), a middle stream to prepare students to study at universities of applied sciences that focus on the practical application of arts and sciences ('HAVO') and another to prepare students for university ('VWO'). More than half of the participants $(57.6 \%)$ were in pre-university education ('VWO'), 8.2\% of the participants was in higher general secondary education to prepare for applied sciences ('HAVO'), and $34.2 \%$ of the participants was in pre-vocational education ('VMBO').

\section{Procedures}

Adolescents and their parents were recruited through secondary schools. We randomly invited 40 secondary schools in the South and the East of the Netherlands to participate in the study. Six secondary schools agreed to participate in wave 1 , and all adolescents attending the first and second grade and their parents were invited to participate in this study by means of an active parental consent procedure. Further details on the study procedures can be found elsewhere [71]. A letter describing the four-wave study was mailed to both parents and they were asked to return a (paper or online) consent form indicating whether they agreed to their child participating in the study and if they agreed to participate in the study themselves. If at least one of their parents' forms was returned, children were rewarded with a small incentive, whether permission was given or not. Before participation, adolescents and parents were informed that participation was voluntary, that they could withdraw from the study at any time and that their answers would be processed anonymously. Inclusion criteria for participants were being enrolled in a high school, being in the first and second grade of this high school, being proficient in the Dutch language and parents and children both having given active informed consent. Exclusion criteria for participants were not being proficient in the Dutch language, attending special education and not having given active (parental) consent.

During one classroom hour of approximately $45 \mathrm{~min}$, adolescents completed an online survey at school, and height and weight were measured outside the classroom 


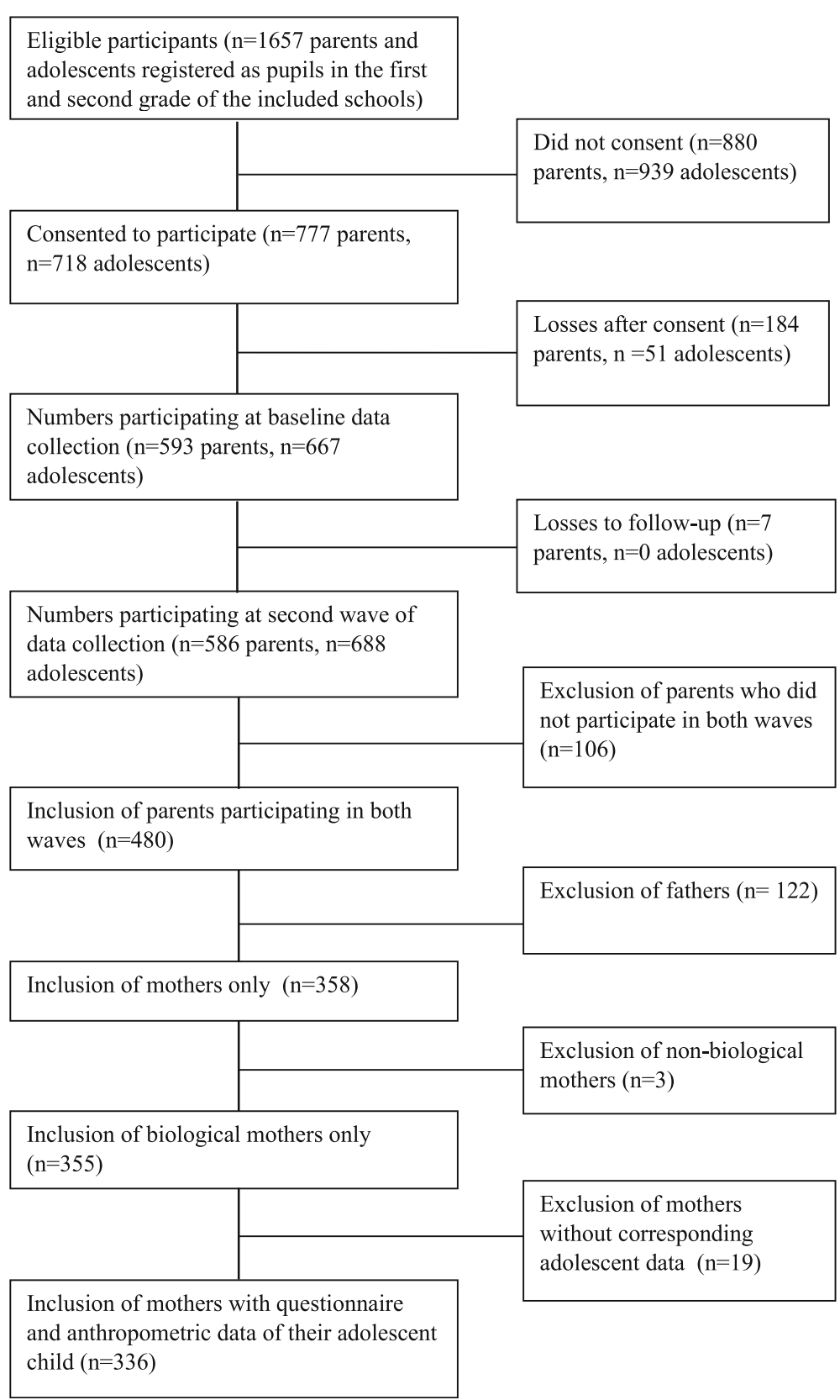

Fig. 1 Flow chart of participation in study sample

by trained research assistants. Parents completed an online survey, which took approximately $20 \mathrm{~min}$ to complete. The questionnaires were administered through Qualtrics Survey Software (Qualtrics, Provo, UT, USA) and were in Dutch language. Children received a small present after completing the survey, and several prizes were raffled among participating parents. The Institutional Review Board of the Faculty of Social Sciences of the Radboud University, Nijmegen, The Netherlands approved the study protocol (reference number ECSW20170805-516) in 2017.

\section{Measures}

Depressive symptoms

Maternal depressive symptoms were assessed with the 10-item short version of the Center for Epidemiological Studies-Depression (CES-D) scale. The CES-D is widely used and has adequate internal reliability [75]. Respondents rated items on a 4-point Likert scale (rarely or none, to most or all the time). The scale includes positive (I was happy) and negative (I could not get going) items. Higher total CES-D scores reflect greater maternal depressive symptomology. In the current study, 
Cronbach's alpha for the CES-D was .77 at T1 and .80 at $\mathrm{T} 2$. The test-retest reliability between $\mathrm{T} 1$ and $\mathrm{T} 2(\mathrm{r}=$ .60) was acceptable, taking into account the period of 6 months between the two questionnaires.

\section{General perceived stress}

Maternal general stress levels were assessed using the 4 item Perceived Stress Scale (PSS). The PSS is a selfreport questionnaire measuring a person's evaluation of stressful situations in the previous 1 month of his or her life. It is a global measure of stress that is simple to use, and there are many studies confirming its reliability and validity in a variety of settings and in multiple languages [76-81]. The instrument contains 4 statements which measure how unpredictable and uncontrollable respondents feel their lives are, for example: In the last month, how often have you felt confident about your ability to handle your personal problems? Respondents rate how often they experience stressful situations on a 5-point Likert scale ranging from 'never' to 'very often'. Answers of the 4 items were summed into a total PSS score. The higher the score on the PSS, the greater the respondent perceives that their demands exceed their ability to cope. Cronbach's alpha was calculated to investigate the internal reliability of the Perceived Stress Scale and was .70 at $\mathrm{T} 1$ and .69 at T2. The test-retest reliability between $\mathrm{T} 1$ and $\mathrm{T} 2(\mathrm{r}=.60)$ was acceptable, taking into account the period of 6 months between the two questionnaires.

\section{Financial stress, stress at work and at home}

Three types of domain-specific stress were measured through three items: financial stress (How often did you experience financial stress in the past year?), stress at work (How often have you felt stress at work in the past year?), and stress at home (How often did you experience stress at home in the past year?). These questions have been used in previous studies to measure different types of stress and are worded in the same manner [82, 83]. Respondents rated how often they experienced stress in the different contexts on a 4-point Likert scale (never, sometimes, regularly, all of the time). The test-retest reliability for financial stress between $\mathrm{T} 1$ and $\mathrm{T} 2(\mathrm{r}=.70)$ was good, taking into account the period of 6 months between the two questionnaires. For stress at home $(r=.60)$ and stress at work $(r=$ $.62)$ the test-retest reliability was acceptable.

\section{Anthropometrics}

Adolescents' height and weight were measured according to protocol [84] by trained research assistants. Body Mass Index (BMI) was calculated as weight in kilograms divided by height in meters squared. Individual age and gender-specific BMI standard deviation scores (z-scores) were calculated using a Dutch representative sample of 0-21-year olds [85, 86]. Mothers reported their own height and weight based on which we calculated maternal BMI.

\section{Covariates}

We controlled for parent's and adolescents' educational level in our regression analyses, as a higher BMI seems to be more frequent in lower educated youth and in youth with lower educated parents [59-61]. We also controlled for additional covariates showing a potential link with adolescent zBMI [62-68]. For example, children are more likely to be overweight or obese in the single-parent (single-mother) family structure [63, 67]. It is known that single household status is associated with having higher time demands due to the lack of shared household responsibilities. Subsequently, a reduction of homemade meals, shared family meals, and physical activity can occur $[63,67]$. Moreover, stress perceived by children themselves seems to alter their energy intake and food selection with a preference for sweet and high fat foods [69] and is associated with adolescent weight status [66]. Furthermore, children and adolescents whose mothers are overweight or obese are more likely to be overweight [62, 67, 70], and gender of the adolescent seems to be a risk factor for developing overweight in adolescence [64]. Depressive symptoms experienced by adolescents themselves $[64,65,87]$ and a poor quality of the child parent-relationship [68] also seem to be risk factors for overweight in children. As such, the following covariates were added: parent's and adolescents' educational level, adolescents' gender, maternal BMI, maternal single household status, adolescent stress and depressive symptoms, as also the quality of the parent-child relationship rated by parents.

Adolescents' educational level was coded as $1=$ pre-vocational education ('VMBO'), 2 = higher general secondary education ('HAVO'), and $3=$ pre-university education ('VWO'). Parents educational level was coded as $1=$ primary $/$ high school, $2=$ secondary vocational education, $3=$ higher professional education/university, following the guidelines of Statistics Netherlands (CBS) [88]. Adolescents' gender was coded as males $=1$ and females $=2$. Maternal BMI was calculated as weight in kilograms divided by height in meters squared. Maternal single household status was coded as $0=$ married or other significant relationship and $1=$ single or no significant relationship. Adolescent stress was measured by asking adolescents to indicate how often they experienced stress at home and at school in the past year on a four point likert scale (rarely or never to most or all the time). We used the mean of these two items by summing them and dividing this by two. Adolescent depressive symptoms were measured with the 10-item short version of the Center for Epidemiological Studies- 
Depression (CES-D) scale, filled out by adolescents. Parents rated the quality of the parent-child relationship on a slider scale from 1 to 100,1 being very low quality and 100 indicating a very high quality.

\section{Statistical analyses}

Statistical analyses were conducted using the PASW 20.0 and $\mathrm{R}$ software package. Descriptive statistics were used (mean, standard deviations and percentages) to describe the study sample and to investigate population characteristics (see Table 1).

First, cross-sectional associations between mothers' wellbeing and adolescent zBMI and the covariates were examined by calculating Pearson's correlation coefficients using SPSS. Second, to test whether maternal stress or depressive symptoms may precede child zBMI over time, multiple linear regression analyses were performed using the $\mathrm{R}$ software package ( $\mathrm{R}$ Core Team, 2018) with depressive symptoms (CES-D score), general stress (PSS score), financial stress, stress at home or stress at work at $\mathrm{T} 1$ as the independent variables, and adolescents' zBMI at T2 as the dependent variable. We examined two models: a multiple linear regression model, adjusted for adolescents' zBMI at baseline and potentially relevant covariates (i.e., educational level of the mother and of the adolescent, gender, maternal BMI, maternal marital status (single household status), the quality of parent/child relationship as rated by parents, child stress, and child depressive symptoms and an unadjusted model without covariates but adjusted for zBMI at baseline. We checked normality and distribution assumptions of zBMI before performing our regression analysis with a scatter plot, QQ plot and the Shapiro Wilk test. The plots showed no extreme outliers and a linear association. The Shapiro Wilk test showed a normal distribution $(\mathrm{W}=.99, p=.53)$.

A logistic regression analysis comparing those adolescents who participated in the current study $($ score $=1)$ with those who could not participate because of lacking maternal data (score $=0$ ) showed no differences in gender, educational level, age and mean zBMI between both groups, we therefore expect no bias. The overall proportion of drop-out from T1 to T2 is relatively low, of the adolescents who gave consent, $95.8 \%$ participated in both waves and $80.9 \%$ of parents participated in both waves. The proportion of missing data in our study sample is also low $(22 / 358=6 \%)$. To account for missing values we used the 'na.exclude' function in $\mathrm{R}$ which does not use the missing values, but maintains their position for the residuals and fitted values.

For the proposed multiple linear regressions, we conducted a sample size analysis using G*Power 3.1 [10]. With a small effect size (f2) of .15, an alpha of .05, a standard power level of .80 , and a total of 14 predictors, the results of the sample size analysis showed that a minimum of 135 participants would be needed to achieve an appropriate power level for this study. Our study sample of 336 parent-child dyads exceeds this number, indicating sufficient power for the proposed analyses.

\section{Results}

\section{Cross-sectional associations and descriptives}

The total sample consisted of 336 adolescent-parent dyads. Mean zBMI of the adolescents was .10 (SD 1.06) at $\mathrm{T} 1$ and .18 (SD 1.07) at $\mathrm{T} 2$. The average change in zBMI from T1 to T2 (6 months interval) was .08 (SD $.99)$, as can be seen in Table 1 .

Pearson's correlation coefficients between maternal wellbeing, covariates and adolescent zBMI are presented in Table 2. Significant correlations were found between maternal depressive symptoms and most of the stress measures, with exception of the 'stress at work' measure. Mostly non-significant correlations were found between maternal wellbeing (i.e., stress or depressive symptoms) and adolescents' zBMI. Of the covariates, maternal BMI was positively correlated with maternal general stress $(\mathrm{r}=.14, p=.03)$, with maternal depressive symptoms $(\mathrm{r}=.12, p=.01)$ and with financial stress $(\mathrm{r}=.18, p=$ .001). Educational level of the adolescent was negatively correlated with maternal depressive symptoms $(\mathrm{r}=-.17$, $p=.003)$ and with maternal general stress $(\mathrm{r}=-.15, p=$ .009). Single household status was correlated with financial stress $(\mathrm{r}=.22, p=.000)$. Quality of parent child relationship was negatively correlated with maternal general stress $(\mathrm{r}=-.19, \mathrm{p}=.001)$ and stress at home $(\mathrm{r}=-.22$, $\mathrm{p}=.000)$.

\section{Longitudinal associations between maternal mental wellbeing and adolescents' zBMI}

Maternal general stress $(\beta=.20, p=.002)$ was associated with adolescent's' zBMI at T2 after correction for baseline zBMI, gender, educational level of the child, educational level of mothers, maternal marital status (single household status), the quality of parent/child relationship as rated by parents, child stress, and child depressive symptoms and maternal BMI as can be seen in Table 3. This effect was still significant in a reduced model without covariates $(\beta=.14, p=.01)$, indicating that maternal general stress is associated with higher zBMI 6 months later. Notably, for the other maternal well-being variables (i.e., maternal financial stress, maternal stress at home, maternal stress at work, maternal depressive symptoms) no significant longitudinal associations were found with adolescents' zBMI, neither in a reduced model nor after controlling for covariates. Additionally, lower educational level among adolescents $(\beta=$ .16, $p=.001)$ and adolescent depressive symptoms $(\beta=$ 
Table 1 Sociodemographic characteristics of the study sample

\begin{tabular}{|c|c|}
\hline & Total study sample ( $N=336$ parents and adolescents) \\
\hline Age of the child (years) at T1; mean (SD) & $12.9(.6)$ \\
\hline Range & $11.3-14.8$ \\
\hline Gender (\% male) & 47.9 \\
\hline Age of the mother (years); mean (SD) & $44.6(4.2)$ \\
\hline Range & $29.8-55.5$ \\
\hline \multicolumn{2}{|l|}{ Educational level mother (\%) } \\
\hline Primary school/high school & 9.4 \\
\hline Secondary vocational education (MBO) & 36.7 \\
\hline Higher professional education (HBO) & 43.3 \\
\hline University & 10.6 \\
\hline \multicolumn{2}{|l|}{ Educational level adolescent (\%) } \\
\hline pre-vocational education (VMBO) & 34.2 \\
\hline higher general secondary education (HAVO) & 8.2 \\
\hline pre-university education ( $\mathrm{WWO}$ ) & 57.6 \\
\hline Adolescent zBMI at T1; mean (SD) & $.10(1.1)$ \\
\hline Range & $-2.9-2.9$ \\
\hline Adolescent zBMI at T2; mean (SD) & $.18(1.1)$ \\
\hline Range & $-2.8-2.9$ \\
\hline \multicolumn{2}{|l|}{ zBMI categories at T1 (\%) } \\
\hline$<-2$ & 1.9 \\
\hline-2 to 2 & 93.7 \\
\hline $2+$ & 4.4 \\
\hline \multicolumn{2}{|l|}{ zBMI categories at T2 (\%) } \\
\hline$<-2$ & 2.4 \\
\hline-2 to 2 & 91.7 \\
\hline $2+$ & 5.8 \\
\hline Maternal BMI score; mean (SD) & $24.6(4.2)$ \\
\hline Range & $16.6-43.0$ \\
\hline Maternal CESD score; mean (SD) & $16.6(3.1)$ \\
\hline Range & $10-30$ \\
\hline Maternal PSS Score; mean (SD) & $7.9(2.2)$ \\
\hline Range & $4-18$ \\
\hline Maternal financial stress; mean (SD) & $1.5(.7)$ \\
\hline Range & $1-4$ \\
\hline Maternal stress at home; mean (SD) & $2.0(.6)$ \\
\hline Range & $1-4$ \\
\hline Maternal stress at work; mean (SD) & $2.1(.7)$ \\
\hline Range & $1-4$ \\
\hline Marital status (single household status) (\%) & 10.1 \\
\hline The quality of parent/child relationship as rated by parents; mean (SD) & $89.2(11.6)$ \\
\hline Range & $17-100$ \\
\hline Child stress; mean (SD) & $1.9(.6)$ \\
\hline Range & $1-4$ \\
\hline Child depressive symptoms & $14.7(3.9)$ \\
\hline Range & $10-33$ \\
\hline
\end{tabular}


Table 2 Correlational associations, $N=336$

\begin{tabular}{|c|c|c|c|c|c|c|c|c|c|c|c|c|c|c|c|}
\hline & 1. & 2. & 3. & 4. & 5. & 6. & 7. & 8. & 9. & 10. & 11. & 12. & 13. & 14. & 15 \\
\hline \multicolumn{16}{|l|}{ Adolescent variables } \\
\hline 1. Adolescent zBMI T1 & 1 & & & & & & & & & & & & & & \\
\hline 2. Adolescent zBMI T2 & $.57^{\mathrm{a}}$ & 1 & & & & & & & & & & & & & \\
\hline \multicolumn{16}{|l|}{ Maternal wellbeing variables } \\
\hline 3. Maternal depressive symptoms & .01 & .02 & 1 & & & & & & & & & & & & \\
\hline 4. Maternal general stress & .003 & .08 & $.55^{\mathrm{a}}$ & 1 & & & & & & & & & & & \\
\hline 5. Maternal stress at work & .000 & .000 & .10 & $.17^{\mathrm{a}}$ & 1 & & & & & & & & & & \\
\hline 6. Maternal financial stress & .09 & .03 & $.19^{\mathrm{a}}$ & $.20^{\mathrm{a}}$ & .01 & 1 & & & & & & & & & \\
\hline 7. Maternal stress at home & .04 & -.01 & $.27^{\mathrm{a}}$ & $.34^{\mathrm{a}}$ & $.14^{\mathrm{b}}$ & $.20^{\mathrm{a}}$ & 1 & & & & & & & & \\
\hline \multicolumn{16}{|l|}{ Covariates } \\
\hline 8. Gender adolescent & -.001 & .04 & .01 & .003 & .02 & .03 & .06 & 1 & & & & & & & \\
\hline 9. Depressive symptoms adolescent & .07 & .08 & .06 & .01 & .03 & .10 & .10 & $.15^{\mathrm{a}}$ & 1 & & & & & & \\
\hline 10. Adolescent stress & .03 & -.01 & .05 & .08 & .03 & .02 & .08 & .10 & $.50^{\mathrm{a}}$ & 1 & & & & & \\
\hline 11. Eucational level adolescent & $-.15^{\mathrm{a}}$ & .03 & $-.17^{\mathrm{a}}$ & $-.15^{\mathrm{a}}$ & .01 & -.09 & .01 & .05 & -.09 & -.02 & 1 & & & & \\
\hline 12. Educational level parent & -.10 & -.09 & -.09 & -.07 & $.18^{\mathrm{a}}$ & -.08 & .07 & .06 & .06 & .06 & $.34^{\mathrm{a}}$ & 1 & & & \\
\hline 13. Maternal BMI T1 & $.30^{\mathrm{a}}$ & $.20^{\mathrm{a}}$ & $.14^{\mathrm{b}}$ & $.12^{\mathrm{b}}$ & -.01 & $.18^{\mathrm{a}}$ & -.04 & .01 & .04 & .02 & $-.22^{\mathrm{a}}$ & $-.17^{\mathrm{a}}$ & 1 & & \\
\hline 14. Relationship status parent & .02 & -.04 & -.02 & .02 & .03 & $.22^{\mathrm{a}}$ & .10 & .05 & $.14^{\mathrm{b}}$ & .06 & -.08 & -.02 & -.03 & 1 & \\
\hline 15. Quality of parent/child relationship & -.02 & -.05 & -.07 & $-.19^{\mathrm{a}}$ & -.08 & .02 & $-.22^{\mathrm{a}}$ & .10 & -.05 & -.03 & -.003 & -.10 & -.004 & -.08 & 1 \\
\hline
\end{tabular}

${ }^{a}$ significant at the 0.01 level (2-tailed). ${ }^{\mathrm{b}}$ significant at the 0.05 level (2-tailed)

$.16, p=.001$ ) were associated with a higher zBMI at T2. The final model (including all covariates) of maternal general stress explained $31 \%$ of the variance of adolescent zBMI.

\section{Discussion}

Longitudinal studies that test whether maternal stress or depressive symptoms may precede the development of adolescents' weight outcomes are rare, and this study aimed to fill this gap. We found that maternal general perceived stress at $\mathrm{T} 1$ preceded higher adolescents' zBMI at T2, after controlling for baseline zBMI and other covariates, whereas maternal depressive symptoms at T1 and other domain-specific stress did not (maternal financial stress, maternal stress at work, maternal stress at home). Additionally, lower educational level among adolescents and adolescent depressive symptoms were associated with a higher zBMI at T2.

In the past decade, several studies have established the link between maternal well-being and childrens' zBMI [28-31,33]. However, these studies mostly focused on (early) childhood. During adolescence, particularly early adolescence, parents still play an important role in their children's lives. Maternal stress and depressive symptoms have been linked to barriers to a healthy lifestyle and may reduce pro-active obesity-related parenting practices $[29,89-91]$ such as less healthy meal preparation and less transportation to and less participation in organized sports by their children, and by for example, negatively influencing mother-child interaction and

Table 3 Linear regressions of maternal stress/depressive symptoms at T1 on adolescent zBMI at T2

\begin{tabular}{|c|c|c|c|c|c|c|c|c|}
\hline & \multicolumn{4}{|c|}{ Analyses adjusted for baseline $\mathrm{zBMI}^{\mathrm{a}}$} & \multicolumn{4}{|c|}{ Analyses adjusted for covariates ${ }^{b}$} \\
\hline & B & SE B & $\beta$ & $P$ value & B & SE B & $\beta$ & $P$ value \\
\hline Maternal general stress & .08 & .03 & .14 & $.01^{*}$ & .10 & .03 & .20 & $.002^{* *}$ \\
\hline Maternal depressive symptoms & -.01 & .02 & -.03 & .49 & -.02 & .02 & -.05 & .44 \\
\hline Maternal financial stress & -.05 & .08 & -.03 & .50 & -.07 & .08 & -.04 & .41 \\
\hline Maternal stress at home & -.07 & .09 & -.04 & .43 & -.09 & .09 & -.06 & .30 \\
\hline Maternal stress at work & -.00 & .08 & -.00 & .97 & .004 & .08 & .003 & .95 \\
\hline $\operatorname{Adj} R^{2}$ & .35 & & & & .31 & & & \\
\hline
\end{tabular}

** significant at the 0.01 level (2-tailed). ${ }^{*}$ significant at the 0.05 level (2-tailed). ${ }^{a}$ Adjusted for: adolescents' zBMI at baseline ${ }^{\mathrm{b}}$ Adjusted for covariates: adolescents' zBMI at baseline, educational level, gender; maternal BMI, educational level of mothers, maternal marital status (single household status), the quality of parent/child relationship as rated by parents, adolescent stress, and adolescent depressive symptoms 
increasing the risk at modelling possibilities of unhealthy maternal behaviors [25, 36, 39, 40, 45-51, 91, 92]. The present study's aim was to investigate the longitudinal link of both maternal stress and depressive symptoms with adolescents' weight development, and we hypothesized that maternal stress and depressive symptoms are linked with increases in adolescents' zBMI development over time. We found a small link between maternal general stress and adolescent zBMI over time, but counter to our hypothesis no significant associations for maternal depressive symptoms or for domain specific stressors (maternal financial stress, stress at home and stress at work) were found.

Maternal general perceived stress may reflect a broader personality construct on how mothers more generally react to stressful situations, whereas stress from the home and work environment probably is more contextual in nature [34]. This may explain why maternal general stress is associated with development of zBMI in adolescents, having more general impact than specific contextual stress factors. Additionally, adolescents with mothers who experience a lot of general stress may be exposed to less healthy family and peer environments, providing increased opportunities to engage in unhealthy behaviors and may lead to unhealthy weight development.

In contrast, no associations were found between maternal depressive symptoms and adolescent zBMI over time. Notably, previous research has already shown some mixed findings particularly with regard to the link between maternal depressive symptoms and children's weight outcomes $[54,55]$. A review reports that chronic depression (depression measured on multiple occasions), but not episodic (depression at a single measurement occasion) depression was found to be associated with a greater risk for child overweight [54]. In our study we measured depressive symptoms at one time point, which may explain why we did not find any associations. However, it should be noted that other studies focusing on episodic symptoms did sometimes find a link with children's weight outcomes [93, 94], though these studies were most often conducted among younger children.

The link between maternal stress and children's weight outcomes have been repeatedly found among families with younger children [28]. To the best of our knowledge, only one previous longitudinal study found this link among adolescents [33]. Our study adds to these previous studies that diverse stress factors have been examined and that only for one specific stress factor longitudinal links have been found (i.e., general stress) in an adolescent population. Thus, it might be that, particularly for adolescents, maternal general stress has more impact on (healthy) family life and adolescents' weight development than maternal stress in other domains and also more impact than maternal depressive symptoms. Future studies including both age groups (i.e., younger children and adolescents) may further examine this.

Socioeconomic factors are also known to be of specific interest in weight development of children and adolescents. We found that a lower educational level among adolescents was consistently associated with a higher zBMI at T2 in all our models. In the Netherlands, children in secondary schools follow education based on their academic level and our study thus suggests that increases in zBMI are most unfavorable in adolescents with a lower educational level. Previous studies have reported about the educational gap with regard to weight outcomes [95]. It seems that the period of adolescence is a particularly important period because of the autonomy involved in making more independent choices about weight related behaviors. Adolescents with lower educational levels may make more unhealthy choices in their weight related behaviors than highly educated adolescents, and may have less (financial) opportunities for healthy weight related behaviors.

Our findings considering adolescent depressive symptoms which consistently were associated with a higher zBMI at T2 in our models are in line with findings of longitudinal studies that depressive symptoms, or depression episodes, during childhood or adolescence are linearly associated with increases in body mass index (BMI), overweight, or obesity over time [87, 96-99]. The link between maternal mental health and child weight development through child mental health issues may be particularly important during adolescence, when depression and stress symptoms are more prevalent compared to childhood [53].

The current study had several strengths and limitations. One particular strength is that height and weight of the adolescents were objectively measured. Another strength includes the fact that parents reported on their own mental health. Additionally, diverse forms of mental health issues, such as general stress and stress which was domain-specific as also depressive symptoms were measured. Despite these strengths, some limitations should be acknowledged. First, the refusal rate on a school level may seem rather high (with 6 out of 40 schools participating). However, the following should be taken into consideration; in the Netherlands, secondary schools are often overloaded with requests for participation in research activities, resulting in the fact that schools are very selective about participation and refusal rates are normally high. With regard to refusal rates at the individual level, the rates are average for the situation in our country. We used an active parental consent procedure. It is known that response rates are higher when passive parental consent (opt-out consent) procedures are used, with estimates as high as $90 \%$, compared to $30-60 \%$ for 
active parental consent procedures [100, 101]. Researchers have consistently found that active parental consent procedures result in lower response rates compared to passive parental consent procedures among middle and high schools students [102, 103]. Our participation rate of $43 \%$ is quite average in this respect. As a second limitation, maternal mental health was analyzed at one time point only, to assess stability in maternal mental state more time points should be taken into account. Third, the time period between the first two waves was relatively short and may not be representative of longer term weight change developments. Fourth, the sample consisted of a high percentage of highly educated respondents $(57.6 \%)$ as well as a high proportion of respondents having a healthy zBMI, possibly influencing the generalizability of the results. School samples recruited with active parental consent procedures are known to be less diverse and have fewer high-risk participants [103]. Additionally, domain-specific stress factors (i.e., financial, home or work-related stress) were only measured with one item. Finally, although we based our research question and analyses on a body of literature that examines the links between maternal stress and adolescent BMI, hypotheses on differential links are quite speculative. As such, we did not formulate separate hypotheses for these differential stress variables.

\section{Conclusions}

To conclude, our findings suggest that adolescents whose mothers experienced more general stress may be at greater risk for increases in zBMI. In contrast, maternal depressive symptoms do not predict any changes in weight development among adolescents. Interventions to increase resources for mothers to cope with stress might help reduce overweight and obesity in their adolescent children. As an additional strategy to address adolescent obesity prevention and intervention, behavioral interventions to help reduce stress such as mindfulness-based stress reduction, could be considered to minimize the effects of stress in mothers on their children's weightrelated behaviors. Our findings warrant future longitudinal investigation with longer follow-ups on whether and how general stress among mothers might predict weight increases of their adolescent offspring.

\footnotetext{
Abbreviations

BMI: Body Mass Index; CES-D: Center for Epidemiological Studies-Depression scale; PSS: Perceived Stress Scale; VMBO: The VMBO is a four-year vocationally-orientated stream focussed on practical knowledge, which leads to vocational training $(\mathrm{MBO})$. It has two qualification levels and students complete the track at the age of 16; HAVO: The HAVO is a five-year middle stream that prepares students to study higher professional education at universities of applied sciences, where they can follow a bachelor's degree in applied sciences (HBO). Students complete the HAVO around the age of 17; WWO: The WWO is a six-year education stream with a focus on theoretical knowledge, that prepares students for a research university (WO). Students complete the stream around the age of 18
}

\section{Acknowledgments}

We would like to thank all the participating schools and families for their contribution to this research project. Moreover, we would like to thank all the research assistants for their help during the data collection of this project.

\section{Declaration of interest statement}

No potential conflict of interest was reported by the authors.

\section{Authors' contributions}

$J V$ and $J L$ were responsible for the study design. $J V$ and $J L$ supervised the data collection. MK was responsible for the statistical analyses and interpretation of the data in agreement with $\mathrm{JV}$, JL, and TV. MK wrote the first version of the manuscript and all authors participated in the revisions of the manuscript. All authors read and approved the final manuscript.

\section{Funding}

We received no specific grant from any funding agency in public, commercial or non-profit sectors. This study was funded by the Behavioural Science Institute of Radboud University in Nijmegen, the Netherlands. The study received no external funding. The analysis and interpretation of the data and the writing of this manuscript were funded by Windesheim University of Applied Sciences and the Behavioural Science Institute of Radboud University in Nijmegen, the Netherlands.

\section{Availability of data and materials}

The datasets generated and analysed during the current study are not publicly available due to agreements we have made concerning the exchange and use of our data, but are available from the corresponding author $[\mathrm{MK}]$ on reasonable request. These data are primary data acquired by (one of) the authors.

\section{Declarations}

\section{Ethics approval and consent to participate}

All procedures performed were in accordance with the ethical standards of the Institutional Review Board of the Faculty of Social Sciences of the Radboud University, Nijmegen, The Netherlands and with the WMA declaration of Helsinki. The study protocol (reference number ECSW20170805-516) was approved in 2017. Written informed consent was obtained from all parents and of individual participants who were included in the study.

\section{Consent for publication \\ Not applicable.}

\section{Competing interests}

The authors declare that they have no competing interests.

\section{Author details}

'Developmental Psychology, Behavioural Science Institute, Radboud University, P.O. Box 9104, 6500, HE, Nijmegen, The Netherlands. ${ }^{2}$ Department of Healthy Society, Knowledge Centre for Health and Social work, Windesheim University of Applied Sciences, Zwolle, The Netherlands. ${ }^{3}$ Hanze University of Applied Sciences, Groningen, The Netherlands.

Received: 14 May 2020 Accepted: 28 March 2021

Published online: 07 April 2021

\section{References}

1. Lytle LA, Seifert S, Greenstein J, McGovern P. How do children's eating patterns and food choices change over time? Results from a cohort study. Am J Health Promot. 2000;14(4):222-8. https://doi.org/10.4278/0890-11 71-14.4.222.

2. Nielsen SJ, Popkin BM. Changes in beverage intake between 1977 and 2001. Am J Prev Med. 2004;27(3):205-10. https://doi.org/10.1016/j.amepre.2004.05. 005.

3. Martens MK, van Assema P, Brug J. Why do adolescents eat what they eat? Personal and social environmental predictors of fruit, snack and breakfast consumption among 12-14-year-old Dutch students. Public Health Nutr. 2005;8(8):1258-65. https://doi.org/10.1079/PHN2005828. 
4. Nelson MC, Neumark-Stzainer D, Hannan PJ, Sirard JR, Story M. Longitudinal and secular trends in physical activity and sedentary behavior during adolescence. Pediatrics. 2006;118(6):e1627-34. https://doi.org/10.1542/peds.2 006-0926.

5. Mann KD, Howe LD, Basterfield L, Parkinson KN, Pearce MS, Reilly JK, et al. Longitudinal study of the associations between change in sedentary behavior and change in adiposity during childhood and adolescence: Gateshead millennium study. Int J Obes. 2017;41(7):1042-7. https://doi.org/1 0.1038/ijo.2017.69.

6. Dietz WH. Critical periods in childhood for the development of obesity. Am J Clin Nutr. 1994;59(5):955-9. https://doi.org/10.1093/ajcn/59.5.955.

7. Ferreira I, Twisk JW, van Mechelen W, Kemper HC, Stehouwer CD. Development of fatness, fitness, and lifestyle from adolescence to the age of 36 years: determinants of the metabolic syndrome in young adults: the Amsterdam growth and health longitudinal study. Arch Intern Med. 2005; 165(1):42-8. https://doi.org/10.1001/archinte.165.1.42.

8. Ogden CL, Carroll MD, Lawman HG, Fryar CD, Kruszon-Moran D, Kit BK, et al. Trends in obesity prevalence among children and adolescents in the United States, 1988-1994 through 2013-2014. JAMA. 2016;315(21):2292-9. https:// doi.org/10.1001/jama.2016.6361.

9. Alberga AS, Sigal RJ, Goldfield G, Prud'homme D, Kenny GP. Overweight and obese teenagers: why is adolescence a critical period? Pediatr Obes. 2012;7(4):261-73. https://doi.org/10.1111/j.2047-6310.2011.00046.x.

10. Neumark-Sztainer D, Story M, Perry C, Casey MA. Factors influencing food choices of adolescents: findings from focus-group discussions with adolescents. J Am Diet Assoc. 1999;99(8):929-37. https://doi.org/10.1016/ S0002-8223(99)00222-9.

11. Freedman DS, Khan LK, Serdula MK, Dietz WH, Srinivasan SR, Berenson GS. The relation of childhood BMI to adult adiposity: the Bogalusa heart study. Pediatrics. 2005;115(1):22-7. https://doi.org/10.1542/peds.2004-0220.

12. Magarey AM, Daniels LA, Boulton TJ, Cockington RA. Predicting obesity in early adulthood from childhood and parental obesity. Int J Obes Relat Metab Disord. 2003;27(4):505-13. https://doi.org/10.1038/sj.ijo.0802251.

13. Singh AS, Mulder C, Twisk JW, van Mechelen W, Chinapaw MJ. Tracking of childhood overweight into adulthood: a systematic review of the literature. Obes Rev. 2008;9(5):474-88. https://doi.org/10.1111/j.1467-789X.2008.00475. $\mathrm{x}$.

14. Herman KM, Craig CL, Gauvin L, Katzmarzyk PT. Tracking of obesity and physical activity from childhood to adulthood: the physical activity longitudinal study. Int J Pediatr Obes. 2009;4(4):281-8. https://doi.org/10.31 09/17477160802596171.

15. Kvaavik E, Tell GS, Klepp Kl. Predictors and tracking of body mass index from adolescence into adulthood: follow-up of 18 to 20 years in the Oslo youth study. Arch Pediatr Adolesc Med. 2003;157(12):1212-8. https://doi.org/10.1 001/archpedi.157.12.1212.

16. Dietz WH. Health consequences of obesity in youth: childhood predictors of adult disease. Pediatrics. 1998;101(3 Pt 2):518-25.

17. Sun SS, Liang R, Huang TT, Daniels SR, Arslanian S, Liu K, et al. Childhood obesity predicts adult metabolic syndrome: the Fels longitudinal study. J Pediatr. 2008;152(2):191-200. https://doi.org/10.1016/j.jpeds.2007.07.055.

18. Agras WS, Hammer LD, Huffman LC, Mascola A, Bryson SW, Danaher C. Improving healthy eating in families with a toddler at risk for overweight: a cluster randomized controlled trial. J Dev Behav Pediatr. 2012;33(7):529-34. https://doi.org/10.1097/DBP.0b013e3182618e1f.

19. Daniels LA, Mallan KM, Battistutta D, Nicholson JM, Meedeniya JE, Bayer JK, et al. Child eating behavior outcomes of an early feeding intervention to reduce risk indicators for child obesity: the NOURISH RCT. Obesity (Silver Spring). 2014;22(5):E104-11. https://doi.org/10.1002/oby.20693.

20. Fisher JO, Birch LL. Restricting access to palatable foods affects children's behavioral response, food selection, and intake. Am J Clin Nutr. 1999;69(6): 1264-72. https://doi.org/10.1093/ajcn/69.6.1264.

21. Hughes SO, Patrick H, Power TG, Fisher JO, Anderson CB, Nicklas TA. The impact of child care providers' feeding on children's food consumption. J Dev Behav Pediatr. 2007;28(2):100-7. https://doi.org/10.1097/01.DBP.0000267561.34199.a9.

22. Loth KA, Friend S, Horning ML, Neumark-Sztainer D, Fulkerson JA. Directive and non-directive food-related parenting practices: associations between an expanded conceptualization of food-related parenting practices and child dietary intake and weight outcomes. Appetite. 2016;107:188-95. https://doi. org/10.1016/j.appet.2016.07.036.

23. Clark HR, Goyder E, Bissell P, Blank L, Peters J. How do parents' child-feeding behaviours influence child weight? Implications for childhood obesity policy. J Public Health (Oxf). 2007;29(2):132-41. https://doi.org/10.1093/ pubmed/fdm012.

24. Rollins BY, Loken E, Savage JS, Birch LL. Maternal controlling feeding practices and girls' inhibitory control interact to predict changes in BMI and eating in the absence of hunger from 5 to 7 y. Am J Clin Nutr. 2014;99(2): 249-57. https://doi.org/10.3945/ajcn.113.063545.

25. Bianchi SM. Maternal employment and time with children: dramatic change or surprising continuity? Demography. 2000;37(4):401-14. https://doi.org/1 0.1353/dem.2000.0001.

26. Masciadrelli P. Paternal involvement by U.S. residential fathers. In: MEL, editor. The role of the father in child development edn. New York: Wiley; 2004. p. 222-71.

27. Holsten JE, Deatrick JA, Kumanyika S, Pinto-Martin J, Compher CW. Children's food choice process in the home environment. A qualitative descriptive study. Appetite. 2012;58(1):64-73. https://doi.org/10.1016/j.a ppet.2011.09.002.

28. Tate EB, Wood W, Liao Y, Dunton GF. Do stressed mothers have heavier children? A meta-analysis on the relationship between maternal stress and child body mass index. Obes Rev. 2015;16(5):351-61. https://doi.org/1 0.1111/obr.12262.

29. Lohman BJ, Stewart S, Gundersen C, Garasky S, Eisenmann JC. Adolescent overweight and obesity: links to food insecurity and individual, maternal, and family stressors. J Adolesc Health. 2009;45(3):230-7. https://doi.org/10.1 016/j.jadohealth.2009.01.003.

30. Garasky S, Stewart SD, Gundersen C, Lohman BJ, Eisenmann JC. Family stressors and child obesity. Soc Sci Res. 2009;38(4):755-66. https://doi.org/1 0.1016/j.ssresearch.2009.06.002.

31. Leppert B, Junge KM, Roder S, Borte M, Stangl GI, Wright RJ, et al. Early maternal perceived stress and children's BMI: longitudinal impact and influencing factors. BMC Public Health. 2018;18(1):1211. https://doi.org/10.11 86/s12889-018-6110-5.

32. Fahrenkamp AJ, Sato AF. Child-specific, maternal, and environmental stressors in the context of adolescent weight outcomes. Child Health Care. 2018;47(4):397-415. https://doi.org/10.1080/02739615.2017.1383910.

33. Shankardass K, McConnell R, Jerrett M, Lam C, Wolch J, Milam J, et al. Parental stress increases body mass index trajectory in pre-adolescents. Pediatr Obes. 2014;9(6):435-42. https://doi.org/10.1111/j.2047-6310.2013.002 08.x.

34. Jang M, Owen B, Lauver DR. Different types of parental stress and childhood obesity: a systematic review of observational studies. Obes Rev. 2019;20(12):1740-58. https://doi.org/10.1111/obr.12930.

35. Gross RS, Velazco NK, Briggs RD, Racine AD. Maternal depressive symptoms and child obesity in low-income urban families. Acad Pediatr. 2013;13(4): 356-63. https://doi.org/10.1016/j.acap.2013.04.002.

36. Milgrom J, Skouteris H, Worotniuk T, Henwood A, Bruce L. The association between ante- and postnatal depressive symptoms and obesity in both mother and child: a systematic review of the literature. Womens Health Issues. 2012;22(3):e319-28. https://doi.org/10.1016/j.whi.2011.12.001.

37. O'Brien M, Nader PR, Houts RM, Bradley R, Friedman SL, Belsky J, et al. The ecology of childhood overweight: a 12-year longitudinal analysis. Int J Obes. 2007;31(9):1469-78. https://doi.org/10.1038/sj.jjo.0803611.

38. O'Connor SG, Maher JP, Belcher BR, Leventhal AM, Margolin G, Shonkoff ET, et al. Associations of maternal stress with children's weight-related behaviours: a systematic literature review. Obes Rev. 2017;18(5):514-25. https://doi.org/10.1111/obr.12522.

39. Morrissey TW, Dagher RK. A longitudinal analysis of maternal depressive symptoms and children's food consumption and weight outcomes. Public Health Nutr. 2014;17(12):2759-68. https://doi.org/10.1017/S13689800130033 76.

40. Gelfand DM, Teti DM. The effects of maternal depression on children. Clin Psychol Rev. 1990;10(3):329-53. https://doi.org/10.1016/0272-7358(90)90065-I.

41. Hurley KM, Black MM, Papas MA, Caulfield LE. Maternal symptoms of stress, depression, and anxiety are related to nonresponsive feeding styles in a statewide sample of WIC participants. J Nutr. 2008;138(4):799-805. https:// doi.org/10.1093/jn/138.4.799.

42. Audelo J, Kogut K, Harley KG, Rosas LG, Stein L, Eskenazi B. Maternal depression and childhood overweight in the CHAMACOS study of MexicanAmerican children. Matern Child Health J. 2016;20(7):1405-14. https://doi. org/10.1007/s10995-016-1937-9.

43. Mora PA, Bennett IM, Elo IT, Mathew L, Coyne JC, Culhane JF. Distinct trajectories of perinatal depressive symptomatology: evidence from growth 
mixture modeling. Am J Epidemiol. 2009;169(1):24-32. https://doi.org/10.1 093/aje/kwn283.

44. McConley RL, Mrug S, Gilliland MJ, Lowry R, Elliott MN, Schuster MA, et al. Mediators of maternal depression and family structure on child BMl: parenting quality and risk factors for child overweight. Obesity (Silver Spring). 2011;19(2):345-52. https://doi.org/10.1038/oby.2010.177.

45. Shloim N, Edelson LR, Martin N, Hetherington MM. Parenting styles, feeding styles, feeding practices, and weight status in 4-12 year-old children: a systematic review of the literature. Front Psychol. 2015;6. https://doi.org/1 0.3389/fpsyg.2015.01849.

46. Gundersen C, Mahatmya D, Garasky S, Lohman B. Linking psychosocial stressors and childhood obesity. Obes Rev. 2011;12(5):e54-63. https://doi. org/10.1111/j.1467-789X.2010.00813.x.

47. Clowtis LM, Kang DH, Padhye NS, Rozmus C, Barratt MS. Biobehavioral factors in child health outcomes: the roles of maternal stress, maternal-child engagement, salivary cortisol, and salivary testosterone. Nurs Res. 2016;65(5): 340-51. https://doi.org/10.1097/NNR.0000000000000172.

48. Wong ST. The relationship between parent emotion, parent behavior, and health status of young African American and Latino children. J Pediatr Nurs. 2006;21(6):434-42. https://doi.org/10.1016/j.pedn.2006.05.002.

49. Lovejoy MC, Graczyk PA, O'Hare E, Neuman G. Maternal depression and parenting behavior: a meta-analytic review. Clin Psychol Rev. 2000;20(5): 561-92. https://doi.org/10.1016/S0272-7358(98)00100-7.

50. Burke $L$. The impact of maternal depression on familial relationships. Int Rev Psychiatry. 2003;15(3):243-55. https://doi.org/10.1080/0954026031000136866.

51. Cummings EM, Davies PT. Maternal depression and child development. J Child Psychol Psychiatry. 1994;35(1):73-112. https://doi.org/10.1111/j.14697610.1994.tb01133.x.

52. Ferris KA, Babskie E, Metzger A. Associations between food-related parenting behaviors and Adolescents' engagement in unhealthy eating behaviors: the role of nutrition knowledge. Int J Aging Hum Dev. 2017;84(3): 231-46. https://doi.org/10.1177/0091415016685325.

53. Larsen JK, Otten R, Fisher JO, Engels RC. Depressive symptoms in adolescence: a poor indicator of increases in body mass index. J Adolesc Health. 2014;54(1):94-9. https://doi.org/10.1016/j.jadohealth.2013.08.001.

54. Lampard AM, Franckle RL, Davison KK. Maternal depression and childhood obesity: a systematic review. Prev Med. 2014;59:60-7. https://doi.org/10.101 6/j.ypmed.2013.11.020.

55. Duarte CS, Shen S, Wu P, Must A. Maternal depression and child BMI: longitudinal findings from a US sample. Pediatr Obes. 2012;7(2):124-33. https://doi.org/10.1111/j.2047-6310.2011.00012.x.

56. Oliver $G$, Wardle J. Perceived effects of stress on food choice. Physiol Behav. 1999;66(3):511-5. https://doi.org/10.1016/S0031-9384(98)00322-9.

57. Zellner DA, Loaiza S, Gonzalez Z, Pita J, Morales J, Pecora D, et al. Food selection changes under stress. Physiol Behav. 2006;87(4):789-93. https://doi. org/10.1016/j.physbeh.2006.01.014.

58. Bauer KW, Hearst MO, Escoto K, Berge JM, Neumark-Sztainer D. Parental employment and work-family stress: associations with family food environments. Soc Sci Med. 2012;75(3):496-504. https://doi.org/10.1016/j. socscimed.2012.03.026

59. Borraccino A, Lemma P, Berchialla P, Cappello N, Inchley J, Dalmasso P, et al. Unhealthy food consumption in adolescence: role of sedentary behaviours and modifiers in 11-, 13- and 15-year-old Italians. Eur J Pub Health. 2016; 26(4):650-6. https://doi.org/10.1093/eurpub/ckw056.

60. van der Horst K, Timperio A, Crawford D, Roberts R, Brug J, Oenema A. The school food environment associations with adolescent soft drink and snack consumption. Am J Prev Med. 2008;35(3):217-23. https//doi.org/10.1016/j.amepre.2008.05.022.

61. Wouters EJ, Larsen JK, Kremers SP, Dagnelie PC, Geenen R. Peer influence on snacking behavior in adolescence. Appetite. 2010;55(1):11-7. https://doi. org/10.1016/j.appet.2010.03.002.

62. Heslehurst N, Vieira R, Akhter Z, Bailey H, Slack E, Ngongalah L, et al. The association between maternal body mass index and child obesity: a systematic review and meta-analysis. PLoS Med. 2019;16(6):e1002817. https://doi.org/10.1371/journal.pmed.1002817.

63. Duriancik DM, Goff CR. Children of single-parent households are at a higher risk of obesity: a systematic review. J Child Health Care. 2019;23(3):358-69. https://doi.org/10.1177/1367493519852463.

64. Mannan M, Mamun A, Doi S, Clavarino A. Prospective associations between depression and obesity for adolescent males and females- a systematic review and meta-analysis of longitudinal studies. PLoS One. 2016;11(6): e0157240. https://doi.org/10.1371/journal.pone.0157240.
65. Quek YH, Tam WWS, Zhang MWB, Ho RCM. Exploring the association between childhood and adolescent obesity and depression: a meta-analysis. Obes Rev. 2017;18(7):742-54. https://doi.org/10.1111/obr.12535.

66. De Vriendt T, Moreno LA, De Henauw S. Chronic stress and obesity in adolescents: scientific evidence and methodological issues for epidemiological research. Nutr Metab Cardiovasc Dis. 2009;19(7):511-9. https://doi.org/10.1016/..numecd.2009.02.009.

67. Gibson LY, Byrne SM, Davis EA, Blair E, Jacoby P, Zubrick SR. The role of family and maternal factors in childhood obesity. Med J Aust. 2007;186(11): 591-5. https://doi.org/10.5694/j.1326-5377.2007.tb01061.x.

68. Haines J, Rifas-Shiman SL, Horton NJ, Kleinman K, Bauer KW, Davison KK, et al. Family functioning and quality of parent-adolescent relationship: cross-sectional associations with adolescent weight-related behaviors and weight status. Int J Behav Nutr Phys Act. 2016;13(1):68. https://doi.org/10.11 86/s12966-016-0393-7.

69. Michels N, Sioen I, Braet C, Eiben G, Hebestreit A, Huybrechts I, et al. Stress, emotional eating behaviour and dietary patterns in children. Appetite. 2012; 59(3):762-9. https://doi.org/10.1016/j.appet.2012.08.010.

70. Hemond J, Robbins RB, Young PC. The effects of maternal obesity on neonates, infants, children, adolescents, and adults. Clin Obstet Gynecol. 2016;59(1):216-27. https://doi.org/10.1097/GRF.0000000000000179.

71. van den Broek N, Larsen JK, Verhagen M, Burk WJ, Vink JM. Is adolescents' food intake associated with exposure to the food intake of their mothers and best friends? Nutrients. 2020;12(3):786. https://doi.org/10.3390/nu1203 0786.

72. Cohen S, Janicki-Deverts D. Who's stressed? Distributions of psychological stress in the United States in probability samples from 1983, 2006, and 2009. J Appl Soc Psychol. 2012;42(6):1320-34.

73. MP. M. Gender differences in stress and coping styles. Personal Individ Differ. 2004;37(7):1401-15. https://doi.org/10.1016/j.paid.2004.01.010.

74. Tooth L, Ware R, Bain C, Purdie DM, Dobson A. Quality of reporting of observational longitudinal research. Am J Epidemiol. 2005;161(3):280-8. https://doi.org/10.1093/aje/kwi042.

75. Andresen EM, Malmgren JA, Carter WB, Patrick DL. Screening for depression in well older adults - evaluation of a short-form of the Ces-D. Am J Prev Med. 1994;10(2):77-84. https://doi.org/10.1016/50749-3797(18)30622-6.

76. Cohen S, Kamarck T, Mermelstein R. A global measure of perceived stress. J Health Soc Behav. 1983;24(4):385-96. https://doi.org/10.2307/2136404.

77. Mezzacappa ES, Guethlein W, Vaz N, Bagiella E. A preliminary study of breast-feeding and maternal symptomatology. Ann Behav Med. 2000;22(1): 71-9. https://doi.org/10.1007/BF02895170.

78. Reis RS, Hino AA, Anez CR. Perceived stress scale: reliability and validity study in Brazil. J Health Psychol. 2010;15(1):107-14. https://doi.org/10.11 77/1359105309346343

79. Mimura C, Griffiths P. A Japanese version of the perceived stress scale: translation and preliminary test. Int J Nurs Stud. 2004;41(4):379-85. https:// doi.org/10.1016/j.jinurstu.2003.10.009.

80. Muller L, Spitz E. Multidimensional assessment of coping: validation of the brief COPE among French population. Encephale. 2003;29(6):507-18.

81. Warttig SL, Forshaw MJ, South J, White AK. New, normative, English-sample data for the short form perceived stress scale (PSS-4). J Health Psychol. 2013;18(12):1617-28. https://doi.org/10.1177/1359105313508346.

82. Ligthart L, Huijgen A, Willemsen G, de Geus EJC, Boomsma DI. Are migraine and tension-type headache genetically related? An investigation of twin family data. Twin Res Hum Genet. 2018;21(2):112-8. https://doi.org/10.1017/ thg.2018.5.

83. Vreeker A, Brunt TM, Treur JL, Willemsen G, Boomsma DI, Verweij KH, et al. Comparing ecstasy users and non-users in a population-based and co-twin control design across multiple traits. Addict Behav. 2020;108:106421. https:// doi.org/10.1016/j.addbeh.2020.106421.

84. Fredriks AM, van Buuren S, Wit JM, Verloove-Vanhorick SP. Body index measurements in 1996-7 compared with 1980. Arch Dis Child. 2000;82(2): 107-12. https://doi.org/10.1136/adc.82.2.107.

85. Schonbeck Y, Talma H, van Dommelen P, Bakker B, Buitendijk SE, Hirasing RA, et al. Increase in prevalence of overweight in Dutch children and adolescents: a comparison of nationwide growth studies in 1980, 1997 and 2009. PLoS One. 2011;6(11):e27608. https://doi.org/10.1371/journal.pone.0027608.

86. Talma H. Groeidiagrammen; 2010.

87. Goodman E, Whitaker RC. A prospective study of the role of depression in the development and persistence of adolescent obesity. Pediatrics. 2002; 110(3):497-504. https://doi.org/10.1542/peds.110.3.497. 
88. Centraal Bureau voor de Statistiek. Opleidingsniveau. 2019. https://www.cbs. nl/nl-nl/nieuws/2019/33/verschil-levensverwachting-hoog-en-laagopgeleidgroeit/opleidingsniveau. Accessed 1 Mar 2021.

89. McCurdy K, Gorman KS, Metallinos-Katsaras E. From poverty to food insecurity and child overweight: a family stress approach. Child Dev Perspect. 2010;4(2):144-51. https://doi.org/10.1111/j.1750-8606.2010.00133.x.

90. Anderson SE, Gooze RA, Lemeshow S, Whitaker RC. Quality of early maternal-child relationship and risk of adolescent obesity. Pediatrics. 2012; 129(1):132-40. https://doi.org/10.1542/peds.2011-0972.

91. Topham GL, Page MC, Hubbs-Tait L, Rutledge JM, Kennedy TS, Shriver L, et al. Maternal depression and socio-economic status moderate the parenting style/child obesity association. Public Health Nutr. 2010;13(8): 1237-44. https://doi.org/10.1017/S1368980009992163.

92. McLearn KT, Minkovitz CS, Strobino DM, Marks E, Hou W. The timing of maternal depressive symptoms and mothers' parenting practices with young children: implications for pediatric practice. Pediatrics. 2006;118(1): e174-82. https://doi.org/10.1542/peds.2005-1551.

93. Ertel KA, Kleinman $K$, van Rossem L, Sagiv $\mathrm{S}$, Tiemeier $\mathrm{H}$, Hofman $\mathrm{A}$, et al. Maternal perinatal depression is not independently associated with child body mass index in the generation R study: methods and missing data matter. J Clin Epidemiol. 2012;65(12):1300-9. https://doi.org/10.1016/j. jclinepi.2012.05.013.

94. Ertel KA, Rich-Edwards JW, Koenen KC. Maternal depression in the United States: nationally representative rates and risks. J Women's Health (Larchmt). 2011;20(11):1609-17. https://doi.org/10.1089/jwh.2010.2657.

95. Gray HL, Buro AW, Barrera Ikan J, Wang W, Stern M. School-level factors associated with obesity: a systematic review of longitudinal studies. Obes Rev. 2019;20(7):1016-32. https://doi.org/10.1111/obr.12852.

96. Franko DL, Striegel-Moore RH, Thompson D, Schreiber GB, Daniels SR. Does adolescent depression predict obesity in black and white young adult women? Psychol Med. 2005;35(10):1505-13. https://doi.org/10.1017/S00332 91705005386.

97. Hasler G, Pine DS, Kleinbaum DG, Gamma A, Luckenbaugh D, Ajdacic V et al. Depressive symptoms during childhood and adult obesity: the Zurich cohort study. Mol Psychiatry. 2005;10(9):842-50. https://doi.org/10.1038/sj. mp.4001671.

98. Pine DS, Cohen P, Brook J, Coplan JD. Psychiatric symptoms in adolescence as predictors of obesity in early adulthood: a longitudinal study. Am J Public Health. 1997;87(8):1303-10. https://doi.org/10.2105/AJPH.87.8.1303.

99. Richardson LP, Davis R, Poulton R, McCauley E, Moffitt TE, Caspi A, et al. A longitudinal evaluation of adolescent depression and adult obesity. Arch Pediatr Adolesc Med. 2003;157(8):739-45. https://doi.org/10.1001/archpedi.1 57.8.739.

100. Smith DC, Boel-Studt S, Cleeland L. Parental consent in adolescent substance abuse treatment outcome studies. J Subst Abus Treat. 2009;37(3): 298-306. https://doi.org/10.1016/j.jsat.2009.03.007.

101. Doumas DM, Esp S, Hausheer R. Parental consent procedures: impact on response rates and nonresponse Bias. J Substance Abuse Alcoholism. 2015; 3(2):1031.

102. Courser MW, Shamblen SR, Lavrakas PJ, Collins D, Ditterline P. The impact of active consent procedures on nonresponse and nonresponse error in youth survey data: evidence from a new experiment. Eval Rev. 2009;33(4):370-95. https://doi.org/10.1177/0193841X09337228.

103. Shaw T, Cross D, Thomas LT, Zubrick SR. Bias in student survey findings from active parental consent procedures. Br Educ Res J. 2014;41(2):229-43.

\section{Publisher's Note}

Springer Nature remains neutral with regard to jurisdictional claims in published maps and institutional affiliations.

Ready to submit your research? Choose BMC and benefit from:

- fast, convenient online submission

- thorough peer review by experienced researchers in your field

- rapid publication on acceptance

- support for research data, including large and complex data types

- gold Open Access which fosters wider collaboration and increased citations

- maximum visibility for your research: over $100 \mathrm{M}$ website views per year

At BMC, research is always in progress.

Learn more biomedcentral.com/submissions 